\title{
A Comparative Analysis of Spectrum and Outcome of Common bacterial Infections in Patients with and without Diabetes-a Prospective Hospital Based Study
}

\author{
Mona Sood D.M., ${ }^{1}$ Fayaz A. Bhat M.D., ${ }^{2}$ Shariq R. Masoodi D.M., ${ }^{3}$ Fayaz A Sofi M.D., ${ }^{4}$ \\ Yasmin Sultana Rahman M.B., ${ }^{5}$ Moomin H. Bhat D.M., ${ }^{6}$ Arshad lqbal Wani M.D., \\ Mir Iftikhar Bashir M.D., ${ }^{8}$ M Ashraf Ganie D.M., ${ }^{9}$ Abdul Hamid Zargar D.M ${ }^{10}$ \\ 1. 6 Senior Residents, ${ }^{3,7,8,9,10}$ Professor Department of Endocrinology, SKIMS \\ ${ }^{2}$ PG Scholar Department of General Medicine, SKIMS \\ ${ }^{4}$ Professor Department of General Medicine, SKIMS \\ ${ }^{5}$ PG Scholar, Department of Pharmacology Katihar Medical College, Katihar, Bihar, India
}

\section{A B S TRACT}

\begin{abstract}
Objective:In this prospective study we analysed clinical spectrum of infections and there outcome in patients with diabetes mellitus and compared it with nondiabeticcontrols admitted in Endocrinology division of a tertiary care hospital.

Methods:This was a prospective, longitudinal study of 242 diabetic and non-diabetic subjects.Patients were studied in terms of clinical picture, biochemical, haematological and microbiological profile, type and severity of infection, treatment received, and final outcome. There were 142 diabetic patients in group 1 and 100 nondiabetic patients in group 2 served as control. Study subjects were followed for a median period of one year ( 52 weeks in diabetics, 65 weeks in non-diabetics) after discharge from the ward.

Results Diabetic patients admitted because of infections were older than their non-diabetic counterparts $(74 \%$ vs $51 \%>50$ years; $p<0.001)$ and mounted less inflammatory response in terms of fever and leucocytosis( $55 \%$ vs $82 \%: P<0.001)$. Urinary tract infections were the commonest infections observed among in-hospital diabetic as well as non-diabetic patients $(36 \%$ vs. $30 \%$; P>0.3).Diabetics contract some specific infections exclusively, like emphysematous pyelonephritis and foot infections, while respiratory infections were more commonly seen in nondiabeticpatients ( $31 \%$ vs. $11 \%$; $P<0.001)$. Staphylococcus aureuswas the commonest organism involved in soft tissue and diabetic foot infections ( $32 \%$ vs. $19 \% ; \mathrm{P}<0.03)$. Though mean hospital stay was equalin either groupbut it was significantly longer in diabetic subjects when statistically adjusted for APACHE score.Comparative mortality rates were higher in non-diabetics with in-hospital deaths, followup deaths and total deaths of $11 \%, 6.1 \%$ and $17.2 \%$ vs $4.9 \%, 4 \%$ and $9.1 \%$ respectively but re-infections on follow-up occurred more in diabetics ( $15 \%$ vs. $2.6 \% ; P=0.005)$.

Conclusion: Poor glycaemic control and less inflammatory response in terms of fever and leucocytosis, longer hospital stay with increased chances of reinfections are poor prognostic indicators for outcomes in diabetic patients admitted with infections. Urinary tract infections and soft tissue infections particularly foot infectionsare causes of concern in our diabetic patients. JMS 2018: 21 (2):84-90

Keywords: Diabetes, Infections, Urinary tract infections.
\end{abstract}

\section{INTRODUCTION}

Type 2 diabetes mellitus has reached an epidemic proportion in many parts of the world. Infections remain a major cause of morbidity and mortality in diabetics in developing regions of the world. ${ }^{[1,2]}$ Many specific infections are more common in diabetic patients and some are almost confined to them; some others run a more severe course with increased risk of complications in patients with

\section{Correspondence}

Dr. Shariq Rashid Masoodi

Professor of Endocrinology, SKIMS, Srinagar

Email: shariq.masoodi@gmail.com diabetes mellitus. ${ }^{[3]}$ Contrary to common belief, the association between diabetes mellitus and increased susceptibility to infection in general is not supported by strong evidence. ${ }^{[4,5]}$ It is the polymorphonuclear leukocyte function which is suppressed along with leukocyte adherence, chemotaxis, and phagocytosis. ${ }^{[6,}$ 7] Foot infections are the most common soft-tissue infections in patients with diabetes besides respiratory tract and urinary tract infections. We have previously documented in 2007 ina retrospective analysis of 380 diabetic patients; longer duration of diabetes, presence of diabetes specific complications and older age are risk factors for development of infections in patients with diabetes. ${ }^{[8]}$ The 
present prospective study was done with the aim to analyse clinical spectrum of infections and their outcome in patients with diabetes mellitus and compare it with nondiabetic patients.

\section{MATERIALAND METHODS}

\section{Study Design}

A prospective, longitudinal study was performed at Sher-iKashmir Institute of Medical Sciences (SKIMS) Srinagar, Kashmir a multi-specialty, 800 bedded, teaching hospital.

\section{Participants}

142 consecutive diabetic patients(GroupA), admitted in department of Endocrinology SKIMS between July 2008 and July2010 because of a bacterial infection; 100 nondiabetic controls, admitted in Department of Internal Medicine because of various bacterial infections (Group B) were also studied. Patients with infection were classified by the admitting physician as diabetics or non-diabetics according to standard definitions(stated below).

\section{METHODS}

In all study patients, complete clinical data along with full biochemical investigations, management and outcome data were recorded. The data were analysed and compared for the spectrum and outcome of infections between diabetic and non-diabetic patients. A written informed consent was obtained from all the subjects. Patients who were not willing to follow were excluded. Study subjects were followed for a median period of one year (52 weeks in diabetics, 65 weeks in non-diabetics) after discharge from the ward.

\section{Definitions \& Criteria:}

\section{Diabetes Mellitus}

A patient was classified as having diabetes mellitus if

1) Diagnosed with diabetes mellitus prior to current hospitalization, regardless of the mode of treatment.

2) Patient was diagnosed to have diabetes mellitus during the hospitalization as per ADA criteria ${ }^{[9]}$ and discharged with a diagnosis of diabetes mellitus. Patients with high blood glucose levels first detected during the hospitalization but with a normal nondiabetic level of HbAlc were not diagnosed as diabetes mellitus but were instead, characterized as having stress hyperglycemia.

\section{Infection}

Recruited subjects were classified to have an infection as Definite or Probable.
Definite- At least one positive culture of blood, urine or other relevant clinical material.

Probable - Cultures were negative but the infection was diagnosed on the basis of clinical suspicion(SIRS criteria) backed by suggestive non microbiologic laboratory studies, like serology, cytology, radiology, etc.

Severity of infection and the host response was assessed as per the APACHE II score

Re-infection: A new episode of bloodstream infection (as defined above) occurring after discharge from the hospital in the followup period.

\section{Outcome Measures:}

Apart from the clinical spectrum, various outcome measures studied included system involved, microbiological spectrum, admission to intensive care unit, need for mechanical ventilation, length of sepsis-related hospital stay, death in the hospital, and re-infection or death on followup. Subjects, who were discharged, were followed for a median period of one year (52 weeks in diabetics, 65 weeks in non-diabetics).

\section{Exclusion Criteria:}

\section{Patients with additional risk factors}

1. Malignancy

2. Congestive heart failure

3. Chronic renal failure

4. Collagen vascular diseases

5. Treated with chemotherapy, radiotherapy, or glucocorticoids for more than 2 weeks

\section{Statistical analysis}

Statistical Package for Social Sciences (SPSS) for Windows, Release 11.5.0, from SPSS Inc., 2002,Chicago, IL, USA was used for statistical analysis. The data were expressed as percentages or Mean $( \pm \mathrm{SD})$ value as necessary. Statistical methods involved included Student's t-test for normally distributed continuous variables and the Pearson Chi-square test or two-tailed Fisher Exact test for categorical variables. ANOVA were used for comparison of more than two continuous variables. Where the data was not normally distributed, a non-parametric test like MannWhitney U test for two-independent samples or KruskalWallis-H test for several independent samples was used. All the values were calculated as two-tailed; a $P$ value $<0.05$ was considered statistically significant. 


\section{RESULTS}

242 subjects were recruited, 142 were diabetic (131 type 2 DM and 11 type1 DM) patients (Group1) and 100 nondiabetics (group2). In group 1 out of 142 patients 55 were male and 87 were female while in group 2- 58 patients were male and 42 were female. Two-thirds of the study subjects were from rural habitat which is consistent with the topography of catchment area of the Institute. Age of study subjects ranged between 10 to 90 years with a mean age of $51.2 \pm 17.1$; diabetic patients had a mean age of $53.0 \pm 14.0$ while that of non-diabetic patients was $49.09 \pm 20.62$ (P $>0.1$ ). Mean duration of diabetes in group1 was 8.0 years with $86 \%$ of patients having mean $\mathrm{Hba} 1 \mathrm{c}>8 \%$. Thus overall glycaemic control was poor in diabetic cohort patient and majority of them $(88 \%)$ were treated with either insulin or insulin with oral antidiabetic drugs. Other demographic, clinical and biochemical characters are shown in table 1 . In Group 1 patients were older with higher fraction of comorbid conditions in comparison of group2. Majority of patients in group $1(48 \%)$ and group $2(31 \%)$ had hypertensionas a comorbid illness besides stroke and cardiovascular complications.

The main presenting features of studied subjects were fever and dysuria seen in almost $66 \%$ and $30 \%$ subjects respectively. There was no major difference in symptomatology in either group except fever and cough which were significantly more common in nondiabetic group. In diabetes mellitus patients the most common infection was urinary tract infection 51(35.91\%), while in non-diabetics respiratory tract infection was most common 31(31\%) (Table 2) Emphysematous pyelonephritis (2 cases) and foot infections were exclusively seen in diabetic patients. Soft tissue infection was mostly seen in diabetic patients. Atypical infections include two cases of emphysematous pyelonephritis andone case of Candidal psoas abscess with superadded bacterial infection. Urinary tract infection in diabetics was mostly caused by E.coli 24(47\%), other organism were Staphylococcus aureus $6(11.76 \%)$, Klebsiella pneumoniae 5(9.8\%); Both treatment groups received intra venus antibiotic in almost equal proportions. Treatment duration and hospital stay was almost similar in both groups.

When immediate outcomes in terms of number of discharges and death were compared in either groups there were more death in group $2(11 \%)$ in comparison of group 1 were $4 \%$ patients expired. The total deaths in both groups, including hospital and on follow up, were also more in nondiabetics. On long term follow up of these patients it was found that though percentage of recovered subjects in either group were almost same $75 \%$ versus $84 \%$ in group 1 and group 2 respectively but chances of reinfection was high in diabetic patients $13 \%$ versus $2 \%$ in nondiabetic patients. Severity of infections, calculated by APACHE II showed that diabetic patients had worse mean APACHE II score with a value of 8.2 in comparison of non diabetic patients with a mean APACHE II score of 6.8. On the basis of APACHE II score, cases and controls were further divided into groups like, $(<9$ and $>9)$ and the outcomes of the patients were compared in terms of hospital stay, immediate hospital and follow up outcome.

On comparing the outcome in terms of discharged and death in studied subjects with APACHE II $<9$ between diabetics and nondiabetics, re-infection was more in diabetics, although there was no significant difference in deaths in two groups. Comparison of hospital stay in patients with APACHE II $>9$ between diabetics and non-diabetics showed more deaths in non-diabetics but re-infection commoner in diabetics. When the final outcome was compared in terms of good and bad, bad outcome included death and re-infection and good for recovery from infection. Diabetics had worse outcome in $22.7 \%$ in comparison to $19.4 \%$ in nondiabetic subjects.

\section{DISCUSSION}

The long held controversial clinical prejudice that infections tend to be commoner and more severe in diabetic patients remains unresolved. Clinical data suggest that hyperglycemia increases the risk for potentially serious infections because of various abnormalities in immune function. A quarter of a century ago, Rayfield, et al ${ }^{[10]}$ showed that $14 \%$ of all deaths in diabetics were caused by infection and that the infection-associated death rate was approximately twice as high as in non-diabetic patients. Whether the higher death rate was due to an increased infection-associated mortality rate or the result of a higher host susceptibility to infection remained unclear.

Thus in our study we compared 142 diabetic patients with 100 nondiabetic patients to compare clinical spectrum and outcome of varied infections in two groups. Patients were studied in terms of clinical picture, biochemical, hematological and microbiological profile, type and severity of infection, treatment received, and final outcome. Study subjects were followed for a median period of one 
year (52 weeks in diabetics, 65 weeks in non-diabetics) after discharge from the ward.

More than $70 \%$ of the diabetic patients with infection had at least one underlying comorbid condition, chiefly hypertension (69\%), neuropathy (25.4\%), ischemic heart disease (4.22\%).

Though overall profile of infections looked similar in the two groups, some infections like urinary tract infections were more commonly seen in diabetic patients $(35 \%$ vs $30 \%$ )and respiratory infections were much more commonly seen in non-diabetics rather than in diabetic patients $(31 \%$ vs. $11 \% ; \mathrm{P}<0.001)$ while foot infections were exclusively seen in diabetic subjects $(22 \%$ vs. zero; $\mathrm{P}<0.001)$. These were consistent with the study by Zargar, et al (urinary tract infections $28.6 \%$, skin and soft tissue infections $14.3 \%$, foot infections $10.4 \%$, and abdomen infections $3.2 \%$ ). ${ }^{[1]}$ In the largest and most recent study, patients with type 1 and type 2 diabetes mellitus were shown to be at increased risk of lower respiratory tract infection, urinary tract infection and skin and mucous membrane infection compared with control hypertensives. ${ }^{[1]]}$

Urinary tract infections mainly presented as dysuria, fever, vomiting. In respiratory tract infection main presentation was cough, breathlessness, fever. In diabetics, fever was less prominent as compared to non-diabetics in our study. It may be due to less immunological response of diabetic patients to inflammation. ${ }^{[12]}$ In our study we had 6(4.2\%) abdominal infections mainly cholecystitis and one liver abscess, 2(1.4\%) emphysematous pyelonephritis, 1(0.7\%) Candidal psoas abscess. Candida glabrata was grown in both abscess as well as in urine while none of these infections were seen in our non-diabetic group. Only $3(2.11 \%)$ cases of tuberculosis were seen in diabetic as compared to $8(8 \%)$ in non-diabetics. It is in contrast of most of previous studies which showed higher percentage of tuberculosis in diabetes mellitus patients. ${ }^{[13]}$ Similarly, some microorganisms like Staphylococcus aureus were often grown in diabetics than in non-diabetics (32\% vs. $19 \%$; $\mathrm{P}<0.03$ ) whereas Pseudomonasaeruginosa was more often grown in non-diabetics than in diabetic subjects ( $7 \%$ vs. $1 \%$; $\mathrm{P}<0.007)$ with overall results showing Staphylococcus aureus as a main organism followed by E.coli and Klebsiella pneumoniae. Klebsiella pneumoniae was 9.5 times more common in diabetics than in non-diabetics. Lye WC, et a ${ }^{[14]}$ in their study reported E.coli as the predominant organism in diabetics as compared to non-diabetics $(\mathrm{p}<0.05)$.

Massodi.SR, et a ${ }^{[8]}$ in 2007 showed soft tissue infections as the most commonly encountered infections in diabetic patients seen in almost $42 \%$ patients while urinary tract infections accounted for a relatively smaller percentage (28.42\%) of infection. Pulmonary infections were reported in $30.2 \%$ in comparison to our study where pulmonary infections were reported in $10.5 \%$ diabetics and $31 \%$ of non-diabetics.

In our study both the groups had almost same duration of hospital stay, with a mean value of $14.20 \pm 5.43$ days and $14.19 \pm 8.91$ days in diabetic and nondiabetic group respectively. Despite similar hospital stay in either group overall mortality rates were higher in group2 (nondiabetic) after adjusting for APACHE II score. In-hospital deaths,followup deaths and total deaths were $11 \%, 6.1 \%$ and $17.2 \%$ in non-diabetic subjects compared to $4.9 \%, 4 \%$ and $9.1 \%$ in diabetic subjects, respectively. Re-infections occurred significantly more in diabetics compared to nondiabetics ( $15 \%$ vs. $2.6 \% ; \mathrm{P}=0.005)$. Higher mortality rate observed in our non-diabetic subjects is likely because these subjects were sicker in terms of GCS score and APACHE score.

In conclusion, this study reveals some important differences in the profile and outcome of infections between diabetic and non-diabetic subjects admitted to a tertiary care hospital. Diabetic patients admitted because of infections were older, higher fraction of them had comorbid illness, poor glycaemic control and less inflammatory response in terms of fever and leucocytosis, longer hospital stay after adjustments than their non-diabetic counterparts. Though urinary tract infections were common infections observed among in-hospital diabetic as well as non-diabetic patients some specific infections were exclusively seen in diabetic, like emphysematous pyelonephritis and foot infections. Respiratory infections were more commonly seen in nondiabetics.OverallStaphylococcus aureus was the commonest organism involved in soft tissue and diabetic foot infections whereas Pseudomonas aeruginosa was more often grown in non-diabetic than in diabetic subjects. The comparative higher mortality in non-diabetics is likely because these patients were sicker as evidenced by their GCS and APACHE scores. 
Table 1: Baseline demographic, clinical and laboratory parameters of patients

\begin{tabular}{|l|l|l|l|}
\hline & $\begin{array}{l}\text { Diabetic(Group 1) } \\
(\mathbf{n = 1 4 2})\end{array}$ & $\begin{array}{l}\text { Non-Diabetic } \\
\text { (Group2) (n=100) } \\
\text { Mean } \pm \text { SD }\end{array}$ & P value \\
\hline Characteristic & 73.9 & 51.0 & $<0.001$ \\
\hline Male gender (\%) & 38.7 & 58.0 & 0.003 \\
\hline Rural habitus (\%) & 66.2 & 66.0 & $>0.9$ \\
\hline Co-morbidities (\%) & 52.1 & 37.0 & 0.02 \\
\hline Hypertension (\%) & 48.6 & 31.0 & 0.006 \\
\hline CAD (\%)* & 4.2 & 2.0 & $>0.3$ \\
\hline Stroke (\%) & 0 & 5 & 0.007 \\
\hline BHP $(\%)^{*}$ & 0.7 & 3.0 & $>0.1$ \\
\hline GCS* & $14.67 \pm 1.12$ & $13.85 \pm 2.22$ & 0.001 \\
\hline MAP*(mmHg) & $97.72 \pm 13.3$ & $88.64 \pm 15.63$ & 0.001 \\
\hline TLC*(mm3) & $10.4 \pm 4.6$ & $11.8 \pm 5.0$ & 0.2 \\
\hline Neutrophils (\%) & $77.3 \pm 6.7$ & $79.7 \pm 11.0$ & 0.5 \\
\hline Hb (gm \%) & $10.7 \pm 2.0$ & $11.7 \pm 2.2$ & 0.001 \\
\hline Glucose(mg/dl) & $230.69 \pm 97.40$ & $92.33 \pm 11.42$ & 0.001 \\
\hline Creatinine(mg/dl) & $1.43 \pm 0.66$ & $1.28 \pm 0.50$ & 0.05 \\
\hline Calcium (mg/dl) & $9.93 \pm 5.72$ & $9.34 \pm 1.17$ & 0.31 \\
\hline Albumin (g/dl) & $3.40 \pm 0.56$ & $3.39 \pm 0.49$ & 0.87 \\
\hline LDH* (u/l) & $453.76 \pm 253.06$ & $58.54 \pm 188.92$ & 0.87 \\
\hline Cholesterol (mg/dl) & $138.80 \pm 39.77$ & $132.92 \pm 35.19$ & 0.23 \\
\hline Triglycerides (mg/dl) & $171.99 \pm 68.28$ & $152.3 \pm 61.90$ & 0.02 \\
\hline
\end{tabular}

Table2: Comparison of system involved between Diabetics and Non Diabetics

\begin{tabular}{|l|l|l|l|l|}
\hline \multirow{2}{*}{ System involved } & \multicolumn{2}{|l|}{ Diabetic patients(n=142) } & \multicolumn{2}{l|}{ Non diabetic patients(n=100) } \\
\cline { 2 - 5 } & $\mathbf{N}$ & $\mathbf{\%}$ & $\mathbf{n}$ & $\mathbf{\%}$ \\
\hline UTI* & 51 & 35.91 & 30 & 30 \\
\hline STI* & 32 & 22.5 & 17 & 17 \\
\hline RTI* & 15 & 10.56 & 31 & 31 \\
\hline Foot Infections & 32 & 22.53 & 0 & 0 \\
\hline GIT infections* & 6 & 4.22 & 0 & 0 \\
\hline CNS* & 0 & 0 & 3 & 3 \\
\hline PUO* & 0 & 0 & 11 & 11 \\
\hline TB* & 3 & 2.11 & 8 & 8 \\
\hline Atypical infections & 3 & 2.12 & 0 & 0 \\
\hline
\end{tabular}

UTI: urinary tract infections,STI: soft tissue infections,RTI: respiratory tract infections,GIT: gastrointestinal tract, CNS: central nervous system,PUO: pyrexia of unknown origin,TB: tuberculosis

Table 3: Comparison of Microorganisms between Diabetics and non-Diabetics

\begin{tabular}{|l|l|l|l|l|}
\hline \multirow{2}{*}{ Microorganism } & \multicolumn{2}{|l|}{ Diabetic $(\mathbf{n}=\mathbf{1 4 2})$} & \multicolumn{2}{l|}{ Non-diabetic (n=100) } \\
\cline { 2 - 6 } & $\mathbf{N}$ & $\mathbf{\%}$ & $\mathbf{N}$ & $\mathbf{\%}$ \\
\hline Staphylococcus aureus & 45 & 31.7 & 22 & 22.0 \\
\hline E.coli & 30 & 21.1 & 12 & 12.0 \\
\hline KlebsiellaPneumoniae & 9 & 6.3 & 5 & 5.0 \\
\hline M.tuberculosis & 3 & 2.8 & 8 & 9.0 \\
\hline Pseudomonasaeruginosa & 1 & 0.7 & 7 & 7.0 \\
\hline Acinetobacterbaumanii & 2 & 1.4 & 1 & 1.0 \\
\hline
\end{tabular}


Table 4: Immediate and follow up outcome in subjects with Apache $\mathrm{II}<9$

\begin{tabular}{|c|c|c|c|c|}
\hline & & Non Diabetic & Diabetic & $\mathbf{P}$ \\
\hline \multicolumn{5}{|l|}{ Outcome at $\mathrm{D} / \mathrm{C}$} \\
\hline - $\quad$ Discharged & $\mathrm{N}$ & 68 & 71 & \multirow[t]{4}{*}{0.121} \\
\hline & $\%$ & 98.6 & 93.4 & \\
\hline \multirow{2}{*}{ - $\quad$ Death } & $\mathrm{N}$ & 1 & 5 & \\
\hline & $\%$ & 1.4 & 6.58 & \\
\hline \multicolumn{5}{|l|}{ Outcome at FU } \\
\hline \multicolumn{4}{|l|}{ Re-infection } & \multirow[t]{5}{*}{0.07} \\
\hline \multirow{2}{*}{$\bullet \quad$ No } & $\mathrm{N}$ & 67 & 68 & \\
\hline & $\%$ & 97.10 & 89.47 & \\
\hline \multirow[t]{2}{*}{ - Yes } & $\mathrm{N}$ & 2 & 8 & \\
\hline & $\%$ & 2.90 & 10.5 & \\
\hline Death on FU & & & & \multirow[t]{5}{*}{0.20} \\
\hline \multirow[t]{2}{*}{ - $\quad$ No } & $\mathrm{N}$ & 68 & 72 & \\
\hline & $\%$ & 98.6 & 94.7 & \\
\hline \multirow[t]{2}{*}{ - $\quad$ Yes } & $\mathrm{N}$ & 1 & 4 & \\
\hline & $\%$ & 1.45 & 5.26 & \\
\hline Total Deaths & & & & \multirow[t]{5}{*}{0.042} \\
\hline \multirow[t]{2}{*}{ - $\quad$ No } & $\mathrm{N}$ & 67 & 67 & \\
\hline & $\%$ & 97.10 & 88.2 & \\
\hline \multirow[t]{2}{*}{ - $\quad$ Yes } & $\mathrm{N}$ & 2 & 9 & \\
\hline & $\%$ & 2.90 & 11.84 & \\
\hline
\end{tabular}

D/C: Discharge, FU:follow up

Table5: Immediate hospital and follow up outcome in subjects with Apache II $>$ 9.

\begin{tabular}{|c|c|c|c|c|}
\hline Outcome & & Non-diabetics & Diabetic & $\mathbf{P}$ \\
\hline \multirow{2}{*}{ - $\quad$ Discharged } & $\mathrm{N}$ & 21 & 64 & \multirow{4}{*}{0.001} \\
\hline & $\%$ & 67.74 & 97.0 & \\
\hline \multirow[t]{2}{*}{ - $\quad$ Death } & $\mathrm{N}$ & 10 & 2 & \\
\hline & $\%$ & 32.26 & 3.03 & \\
\hline \multicolumn{4}{|l|}{ Re infection } & \multirow{5}{*}{0.02} \\
\hline \multirow{2}{*}{$\bullet \quad$ No } & $\mathrm{N}$ & 31 & 56 & \\
\hline & $\%$ & 100 & 84.8 & \\
\hline \multirow[t]{2}{*}{ - $\quad$ Yes } & $\mathrm{N}$ & 0 & 10 & \\
\hline & $\%$ & 0 & 15.15 & \\
\hline \multicolumn{4}{|l|}{ Deaths } & \multirow{4}{*}{0.018} \\
\hline \multirow[t]{2}{*}{ - $\quad$ No } & $\mathrm{N}$ & 27 & 65 & \\
\hline & $\%$ & 87.10 & 98.5 & \\
\hline \multirow{2}{*}{ - Yes } & $\mathrm{N}$ & 4 & 1 & \\
\hline & $\%$ & 12.9 & 1.5 & \multirow{6}{*}{0.001} \\
\hline \multicolumn{4}{|l|}{ Total deaths } & \\
\hline \multirow[t]{2}{*}{ - $\quad$ No } & $\mathrm{N}$ & 17 & 63 & \\
\hline & $\%$ & 54.84 & 95.45 & \\
\hline \multirow[t]{2}{*}{ - $\quad$ Yes } & $\mathrm{N}$ & 14 & 3 & \\
\hline & $\%$ & 45.16 & 4.55 & \\
\hline
\end{tabular}




\section{REFERENCES}

1. Hamid Zargar A, Iqbal Wani A, Rashid Masoodi S, Ahmad Laway B, Iftikhar Bashir M. Mortality in diabetes mellitusdata from a developing region of the world. Diabetes Research and Clinical Practice. 1999;43(1):67-74.

2. Hamid Zargar A, Rashid Masoodi S, Ahmad Laway B, Akhtar MA. Incidence and pattern of infections in diabetes mellitus. Int J Diab Developing Countries 1994; 14:82- 4 .

3. Joshi N, Caputo G, Weitekamp M, Karchmer A. Infections in Patients with Diabetes Mellitus. New England Journal of Medicine. 1999;341(25):19061912.

4. Wheat L. Infection and Diabetes Mellitus. Diabetes Care. 1980;3(1):187-197

5. Thornton G. Infections and Diabetes. Medical Clinics of North America. 1971;55(4):931-938.

6. Valerius N, Eff C, Hansen N, Karle H, Nerup J, Søeberg B et al. Neutrophil and Lymphocyte Function in Patients with Diabetes Mellitus. ActaMedicaScandinavica. 2009;211(6):463-467

7. Gallacher S, Thomson G, Fraser W, Fisher B, Gemmell C, MacCuish A. Neutrophil Bactericidal Function in Diabetes Mellitus: Evidence for Association with Blood Glucose Control. Diabetic Medicine. 1995;12(10):916-920.

8. Masoodi S, Wani A, Misgar R, Gupta V, Bashir M, Zargar A. Pattern of infections in patients with diabetes mellitusData from a tertiary care medical centre in Indian sub-continent. Diabetes \& Metabolic Syndrome: Clinical Research \& Reviews. 2007;1(2):91-95.

9. Pometta D, Rees S, Younger D, Kass E. Asymptomatic Bacteriuria in Diabetes Mellitus. New England Journal of Medicine. 1967;276(20):1118-1121.

10. Rayfield, E., Ault, M., Keusch, G., Brothers, M., Nechemias, C. and Smith, H. (1982). Infection and Diabetes: The Case for Glucose Control. The Journal of Urology, 128(6), p.1412.

11. Muller, L., Gorter, K., Hak, E., Goudzwaard, W., Schellevis, F., Hoepelman, A. and Rutten, G. (2005). Increased Risk of Common Infections in Patients with Type 1 and Type 2 Diabetes Mellitus. Clinical Infectious Diseases, 41(3), pp.281-288.

12. N E Mowat, A. and Baum, J. (1971). Chemotaxis of Polymorphonuclear Leukocytes from Patients with Diabetes Mellitus. New England Journal of Medicine, 284(12), pp.621-627

13. Surya Kirami KRL,Santha Kumara, LukhmiKumara R. (1998) Coexistence of pulmonary tuberculosis and diabetes mellitus, some observations. Indian Journal of Tuberculosis. 45, pp. 47-48.

14. Lye, W., Chan, R., Lee, E. and Kumarasinghe, G. (1992). Urinary tract infections in patients with diabetes mellitus. Journal of Infection, 24(2), pp.169174. 